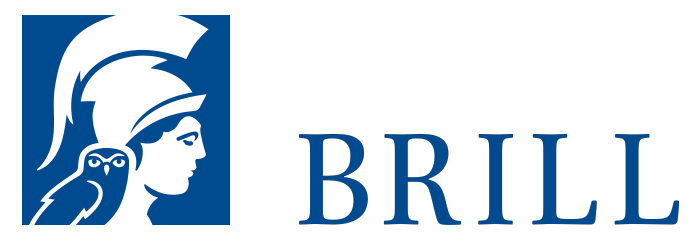

\title{
Perspektiven - Forschungsfragen der Zukunft
}

\author{
Authors: Jörg Behler, Saskia F. Fischer, Andreas Funke, \\ Bernd J. Hartmann, Ulrich Heimhofer, Wim Martens, and \\ Kai Müller
}

Die Nordrhein-Westfälische Akademie der Wissenschaften und der Künste ist eine Vereinigung der führenden Forscherinnen und Forscher des Landes. Sie wurde 1970 als Nachfolgeeinrichtung der Arbeitsgemeinschaft für Forschung des Landes Nordrhein-Westfalen gegründet. Die Akademie ist in drei wissenschaftliche Klassen für Geisteswissenschaften, für Naturwissenschaften und Medizin sowie für Ingenieur- und Wirtschaftswissenschaften und in eine Klasse der Künste gegliedert.

Mit Publikationen zu den wissenschaftlichen Vorträgen in den Klassensitzungen, zu öffentlichen Veranstaltungen und Symposien will die Akademie die Fach- und allgemeine Öffentlichkeit über die Arbeiten der Akademie und ihrer Forschungsstellen informieren.

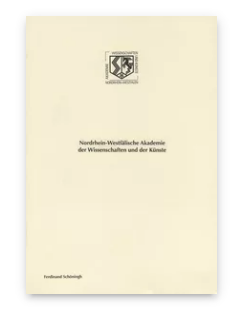

Pages: 89 Seiten, $1 \mathrm{~s} / \mathrm{w}$ und 8 farb.

Abb.

Language:

German

Subjects:

General,

Philosophy

Publisher: Brill |

Schöningh

Series:

Nordrhein-

Westfälische

Akademie der

Wissenschaften und der Künste -

Junges Kolleg

E-Book (PDF)

Released online:

O3 Feb $202 \mathrm{O}$

ISBN: 978-3-

657-7718o-6

List price

USD $\$ 52.00$

Paperback

Publication date: 2o Apr 2011

ISBN: 978-3-

5o6-77180-3

List price

USD $\$ 52.00$ 
For more information see brill.com

Order information: Order online at brill.com +44330 333 0049 | customerservices@brill.com Submission information: brill.com/authors

Titles published by Brill | Fink, Brill | mentis or Brill | Schöningh: +49(o)715413279216| brill@brocom.de 